\title{
Experiences and Opinions of Patients and Their Relatives to Family Presence During Adult Resuscitation in Poland: Quantitative Research
}

This article was published in the following Dove Press journal: Patient Preference and Adherence

\author{
Edyta Niemczyk (D) \\ Dorota Ozga (1) \\ Andrzej Przybylski (iD) ${ }^{2}$ \\ 'Institute of Health Sciences, Collegium \\ Medicum, The University of Rzeszow, \\ Rzeszow 35-310, Poland; ${ }^{2}$ Institute of \\ Medical Sciences, Collegium Medicum, \\ University of Rzeszow, Rzeszow 35-310, \\ Poland
}

\begin{abstract}
Purpose: Scientific research and public opinion polls indicate that the majority of patients and their families believe that members of the patients' family should be offered the opportunity to be present during CPR, at the moment of their loved one's death, and throughout all aspects of emergency care. The study was designed to analyse the experiences and opinions of patients and family members towards Family Presence During Resuscitation (FPDR) in hospitals in Poland.
\end{abstract}

Patients and Methods: We conducted a survey related to FPDR among patients and their families during 5 months in 2017. That was preceded by a pilot study. We asked the patients and the people accompanying them to complete the questionnaire during admission to the hospital; 1000 questionnaires (500 patient responses and 500 family responses) were included in the analysis.

Results: Patients and their relatives more often wanted to be present during resuscitation of a loved one than they agreed to the presence of the family during their resuscitation. The vast majority of patients did not know the patient's rights regarding FPDR. 24.2\% of patients and $29.2 \%$ of their relatives participated in the discussions on FPDR. The interest in FPDR indicated $29.0 \%$ of patients and $27.6 \%$ of family members.

Conclusion: In our survey study, both patients and their family members had a negative attitude towards FPDR. Respondents (both patients and family members) had a low level of awareness that their potential to be present during CPR was included in the patient's rights. Keywords: patient perspective, quality of health care, family

\section{Introduction}

The concept of FPDR has been presented and analysed since the 1980s. FPDR originated in 1982 in Foote Hospital in Jackson, Michigan, USA after a patient's family requested it. ${ }^{1}$ FPDR is defined as the presence of relatives in the place of the patient's care which simultaneously provides visual or physical contact with the patient during procedures or events related to resuscitation. ${ }^{2,3}$ The main aim of FPDR is to satisfy the emotional needs of the patients and their relatives. Although the European Resuscitation Council (ERC) recommends FPDR, ${ }^{4}$ the presence of the members of the patient's family during resuscitation is still under discussion in many countries. The implementation of FPDR into clinical practise poses several obstacles, i.e. legal, ethical and procedural. It should be taken into account that nursing staff find it hard to refer to FPDR due to the lack of clinical practice and relevant experience, as it was comprehensively described in the latest papers by Powers et al. ${ }^{5,6}$ However, the
Correspondence: Dorota Ozga

Tel +48 I7857/955

Email gdozga@poczta.fm 
data concerning the patients' and their families attitudes towards FPDR is scarce. The aim of the study was to analyse the patients' and their families attitudes towards FPDR on the basis of selected hospitals in Poland.

\section{Methods}

\section{Design}

We conducted a cross-sectional survey study.

\section{Setting and Sampling}

Detailed data regarding the place of the research and inclusion criteria are presented in Figure 1.

\section{Questionnaire}

The questionnaires used in the study were prepared on the basis of a literature review entitled "The presence of the patient's family members during the hospital CPR", and were addressed to patients and members of their families. Questionnaires consisted of two pages and had two parts. Part I was "Information for the patient/family member involved in the scientific study". The information contained therein was: an invitation to participate in the study, the purpose of the study, a glossary of terms used in the study (Cardio-pulmonary resuscitation - CPR) - life support activities. CPR is performed in the case of sudden cardiac arrest (SCA), adult patient - a person over 18 years of age, a family member - the person/s who are most important to the patient and entitled to care, family presence - a situation where a family member is present and observes all life-saving interventions) and informed consent to participate in the study. Part II of the questionnaire was divided into II sections (section I-4 questions: sex, age, education, relationship with the medical profession and section II - 7 questions, including 6 closed and 1 open question, which concerned the experiences and opinions of patients and family members to FPDR). The questions were formulated in a simple and closed way. Prior to the study, a pilot survey was conducted in January 2017. Its assessment consisted of two stages. First, we collected all the doubts resulting from the analysis of the responses and from comments made directly by the respondents; changes were suggested based on that. The research team took these suggestions into account in improving the

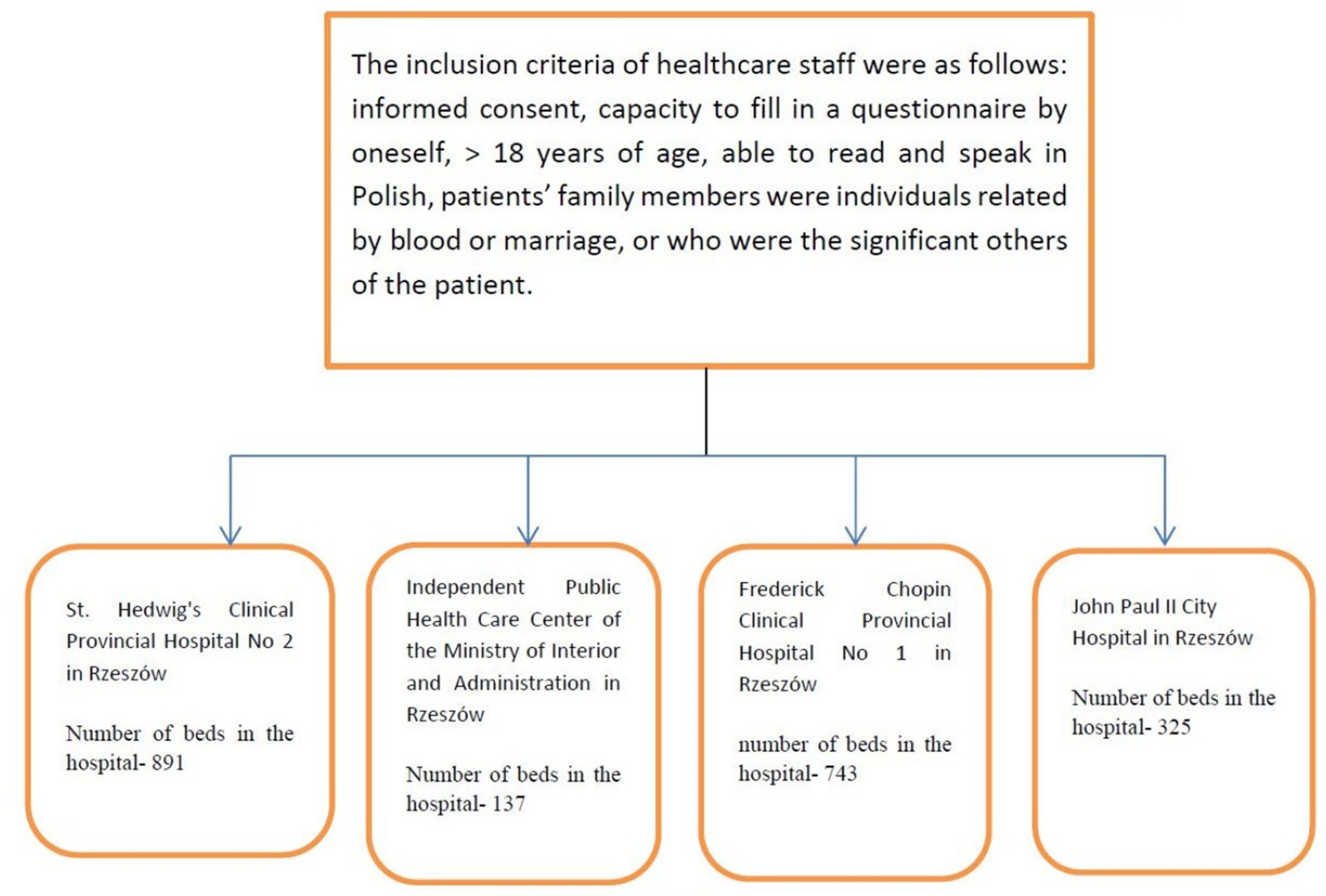

Figure I Inclusion criteria and a list of test sites. 
survey addressed to patients and their families. During the second stage, conclusions were formulated to include all the modifications made in the questionnaire, and the final construct was approved. The analysis of the scale's reliability for the patient was 0.67 of the $\alpha$-Cronbach, and for the scale for family members, it was 0.64 of $\alpha$-Cronbach.

\section{Data Collection}

Participation in the study was voluntary, the patient was guaranteed a sense of confidentiality of the conducted research and informed that the obtained data would be used only for scientific purposes. The research was carried out from March 1 to July 31, 2017. The selection of the test sample was deliberate. All the patients meeting the criteria were included in the study successively during their admission to the hospital. Detailed information is shown in Figure 1. Patients were informed about the purpose of the study, and they were given a place where they could pick the questionnaire and return into a suitably marked box. Research did not pose a threat to human life and health. They were carried out with the consent of the Bioethics Committee of the University of Rzeszow (Resolution No. 5/1/2017 and Resolution No. 13/4/2017). The consent of hospital administration was obtained for conducting scientific research.

\section{Statistical Analysis}

The statistical analysis was carried out in the Statistical 10 and 12 software. A questionnaire regarding FPDR was carried out among the patients and their families. The analysis of the questionnaire reliability was carried out by calculating the Alfa-Cronbach ratio. The level of statistical significance was adopted at $p<0.05$. The relationship between sociodemographic variables and isolated dependent variables was analysed using the Kruskal-Wallis (H) test.

\section{Results}

\section{The Study Group Characteristics}

The study included all patients who voluntarily filled out a questionnaire and returned it into a specially marked box. From this group, 500 questionnaires filled in by patients and 500 complete questionnaires filled in by the patients' family members were included in the study.

The group was characterized with respect to sex, age, degree of relationship, education, and relationship with the medical profession. Detailed characteristics of the respondents are presented in Table 1.
Table I Respondents' General Characteristics

\begin{tabular}{|l|l|}
\hline Patient Characteristics & $\mathbf{n}=\mathbf{5 0 0}$ \\
\hline Age, years; SD & $46.33 \pm$ I7.54 [18-89] \\
Woman $(\mathrm{n}=36)$ & $279(55.8)$ \\
Man $(\mathrm{n}=74)$ & $221(58.2)$ \\
Education, $\mathrm{n}(\%)$ & $106(21.2)$ \\
$\quad$ Vocational & $194(38.8)$ \\
Secondary & $158(31.6)$ \\
Higher & $42(8.4)$ \\
Other & $\mathbf{n}=\mathbf{5 0 0}$ \\
\hline Family Member Characteristics & $43.41 \pm 15.42$ [18-92] \\
\hline Age, years; SD & $291(58.2)$ \\
Woman ( $=36)$ & $209(41.8)$ \\
Man ( $=74)$ & $97(19.4)$ \\
Education, $n$ (\%) & $220(44.0)$ \\
Vocational & $166(33.2)$ \\
Secondary & $\mathbf{1 7}(3.5 \%)$ \\
Higher & \\
Other &
\end{tabular}

97 patients (19.4\%) and 88 family members (17.6\%) had connections to the medical profession. 244 patients (48.8\%) and 265 family members had taken part in a BLS AED training (265 people - 53.0\%). 41.0\% and 36.6\%, respectively, did not take part in such training, no related information was provided by $10.2 \%$ and $10.4 \%$ of the respondents. 80 patients (16.0\%) and 82 family members (16.4\%) had received BLS AED first-aid training.

\section{Attitudes of the Patients and Their Relatives with Respect to FPDR}

The results of the survey revealed that both patients and family members more often wanted to witness resuscitation of a loved one: a patient (29\%), family member (27.6\%), rather than consent to the presence of the family during their own resuscitation: patient (21.2\%) family member (20.2\%) for patients $(\mathrm{p}=0.006)$, and for family member $(\mathrm{p}=0.087)$.

$50 \%$ of patients and $31.4 \%$ family members $(p=0.027)$ lacked knowledge of patient's rights. Only 131 patients (26.2\%) and 157 family members (31.4\%) were aware of the fact that FPDR is one of the patient's rights. 121 (24.2\%) of patients and 146 (29.2\%) of family members had participated in discussions related to FPDR, while this topic had never been discussed with a group of $332(66.4 \%)$ patients and 291 (58.2\%) family members; a lack of knowledge was reported by 47 (9.4\%) and 63 (12.6\%) participants, respectively. The topic was discussed more often by the families than the patients themselves $\left(\chi^{2}(2)=7.36 \mathrm{p}=0.025\right)$. 
The willingness to be present during resuscitation of a loved one was declared by 145 patients (29.0\%) and 138 family members (27.6\%), a lack of acceptance by 231 (46.2\%) and $216(43.2 \%)$ respectively, no opinion by 124 (24.8\%) and $146(29.2 \%)$. There was no difference in the acceptability of family presence by participant type $(\mathrm{p}=$ 0.290). 106 patients (21.2\%) and 101 family members (20.2\%) expressed consent for FPDR, while 265 (53.0\%) and 263 (52.6\%) lacked consent, respectively, and no opinion was expressed by 129 (25.8\%) and 136 (27.2\%) $\left(\chi^{2}(2)=0.31 \mathrm{p}=0.855\right)$. Both patients and the family members more often expressed their willingness to participate in the resuscitation of a loved one rather than accepting the presence of a loved one during their own resuscitation. The patients' and family members' attitude towards and acceptance of FPDR are presented in Table 2.

If family presence during their own CPR was acceptable, patients most often indicated a preference for their spouses and daughters to be present: $19.6 \%$ of patients indicated the husband, $18.7 \%$ indicated the wife and $13.1 \%$ indicated the daughter. When family members

Table 2 Willingness to Be Present During Resuscitation of a Loved One and Acceptance of the Presence of a Family Member During One's Own CPR

\begin{tabular}{|c|c|c|c|c|}
\hline $\begin{array}{l}\text { Presence During } \\
\text { Resuscitation of a Loved } \\
\text { One and Acceptance of the } \\
\text { Presence of a Family } \\
\text { Member During One's Own } \\
\text { CPR }\end{array}$ & \multicolumn{2}{|c|}{$\begin{array}{l}\text { Willingness } \\
\text { to Be Present } \\
\text { During } \\
\text { Resuscitation } \\
\text { of a Loved } \\
\text { One }\end{array}$} & \multicolumn{2}{|c|}{$\begin{array}{l}\text { Acceptance } \\
\text { of the } \\
\text { Presence of } \\
\text { a Family } \\
\text { Member } \\
\text { During } \\
\text { One's Own } \\
\text { CPR by the } \\
\text { Respondent }\end{array}$} \\
\hline PATIENT & $\mathrm{n}$ & $\%$ & $\mathrm{n}$ & $\%$ \\
\hline Yes & 145 & $29.0 \%$ & 106 & $21.2 \%$ \\
\hline No & 231 & $46.2 \%$ & 265 & $53.0 \%$ \\
\hline Does not know & 124 & $24.8 \%$ & 129 & $25.8 \%$ \\
\hline Total & 500 & $100.0 \%$ & 500 & $100.0 \%$ \\
\hline B & \multicolumn{4}{|c|}{$Z=2.70 p=0.006$} \\
\hline FAMILY & $\mathrm{n}$ & $\%$ & $n$ & $\%$ \\
\hline Yes & 138 & $27.6 \%$ & 101 & $20.2 \%$ \\
\hline No & 216 & $43.2 \%$ & 263 & $52.6 \%$ \\
\hline Does not know & 146 & $29.2 \%$ & 136 & $27.2 \%$ \\
\hline Total & 500 & $100.0 \%$ & 500 & $100.0 \%$ \\
\hline$P$ & \multicolumn{4}{|c|}{$Z=1.70 p=0.087$} \\
\hline
\end{tabular}

Notes: $\mathrm{n}$ - number of observations; \% - percentage, $\mathrm{Z}$ - Wilcoxon pairs test result; $\mathrm{P}-$ level of probability.
Table 3 Persons Indicated by the Respondents to Be Present at CPR

\begin{tabular}{|l|l|l|l|l|}
\hline \multirow{2}{*}{$\begin{array}{l}\text { Persons Indicated by the } \\
\text { Respondents to Be Present at } \\
\text { CPR }\end{array}$} & \multicolumn{2}{|l|}{ Patient } & \multicolumn{2}{l|}{ Family } \\
\cline { 2 - 5 } & $\mathbf{n}$ & $\%$ & $\mathbf{n}$ & $\%$ \\
\hline Wife & 20 & $18.7 \%$ & 27 & $28.4 \%$ \\
Husband & 21 & $19.6 \%$ & 35 & $36.8 \%$ \\
Partner & 1 & $0.9 \%$ & 0 & $0.0 \%$ \\
Children & 3 & $2.8 \%$ & 2 & $2.1 \%$ \\
Daughter & 14 & $13.1 \%$ & 9 & $9.5 \%$ \\
Son & 8 & $7.5 \%$ & 5 & $5.3 \%$ \\
Parents & 6 & $5.6 \%$ & 0 & $0.0 \%$ \\
Mother & 6 & $5.6 \%$ & 4 & $4.2 \%$ \\
Father & 2 & $1.9 \%$ & 3 & $3.2 \%$ \\
Sister & 5 & $4.7 \%$ & 1 & $1.1 \%$ \\
Brother & 3 & $2.8 \%$ & 3 & $3.2 \%$ \\
Brother-in-law & 1 & $0.9 \%$ & 0 & $0.0 \%$ \\
Relative & 12 & $11.2 \%$ & 3 & $3.2 \%$ \\
Priest & 1 & $0.9 \%$ & 0 & $0.0 \%$ \\
Medical staff & 2 & $1.9 \%$ & 1 & $1.1 \%$ \\
Trained person & 1 & $0.9 \%$ & 2 & $2.1 \%$ \\
Does not matter & 3 & $2.8 \%$ & 0 & $0.0 \%$ \\
Does not know & 1 & $0.9 \%$ & 0 & $0.0 \%$ \\
Total & 107 & $100.0 \%$ & 95 & $100.0 \%$ \\
\hline P & $\chi^{2}(17)=30.04$ & $\mathrm{P}=0.026$ \\
\hline Notes n- num & & & \\
\hline
\end{tabular}

Notes: $\mathrm{n}$ - number of observations; \% - percentage, $\chi^{2}$ - the Pearson chi-square test result; $\mathrm{p}-$ level of probability.

were in agreement of family presence, $36.8 \%$ indicated the husband, $28.4 \%$ indicated the wife and $9.5 \%$ the daughter. Individuals indicated by the patients were more diverse than the persons indicated by the family members, which was confirmed in the statistical significance test $\left(\chi^{2}\right.$ $(17)=30.04 \mathrm{p}=0.026)($ Table 3$)$.

131 patients (26.2\%) and 157 (31.4\%) family members were aware of the fact that FPDR is one of patient's rights. The difference in this knowledge between the two groups was statistically significant $\left(\chi^{2}(2)=16 \mathrm{p}=0.027\right)$ (Table 4).

\section{Discussion}

Until recently, it was a rule that the patient's family was absent during life-saving procedures. Perhaps one of the reasons for this conduct was the paternalistic attitude of the medical staff, who assumed that the presence of the loved ones would complicate and impede the correct implementation of the procedure increasing anxiety among the family and the patient at the same time. Research and public opinion polls suggest that the majority of patients and their families believe that family should be offered the opportunity to be present during CPR and at the moment of their loved one's death. The European Resuscitation Council (ERC) recommends that 
Table 4 Participants' Knowledge Regarding the Patient's Consent for FPDR

\begin{tabular}{|l|l|l|l|l|}
\hline \multirow{2}{*}{$\begin{array}{l}\text { Awareness That FPDR Is } \\
\text { a Patient's Right }\end{array}$} & \multicolumn{2}{l|}{ Patient } & \multicolumn{2}{l|}{ Family } \\
\cline { 2 - 6 } & $\mathbf{n}$ & $\%$ & $\mathbf{n}$ & $\%$ \\
\hline Yes & 131 & $26.2 \%$ & 157 & $31.4 \%$ \\
No & 70 & $14.0 \%$ & 86 & $17.2 \%$ \\
Does not know & 299 & $59.8 \%$ & 257 & $51.4 \%$ \\
Total & 500 & $100.0 \%$ & 500 & $100.0 \%$ \\
\hline P & \multicolumn{3}{|l|}{$\chi^{2}(2)=16 \mathrm{p}=0.027$} \\
\hline
\end{tabular}

Notes: $\mathrm{n}$ - number of observations; $\%$ - percentage, $\chi^{2}-$ the Pearson chi-square test result; $\mathrm{p}$ - level of probability.

health professionals allow family members to be present during resuscitation. ${ }^{4}$ Although many benefits of FPDR have been identified, this issue practice continues to generate ethical, moral and legal dilemmas among health care workers. ${ }^{5-7}$

Our research is the largest study to investigate the attitude of patients' and their families towards FPDR. In contrast with a data derived from the literature, our study shows that both patients and their family members have a negative attitude towards FPDR. Only $29 \%$ of the surveyed patients and $27.6 \%$ of their families expressed a desire to be present during the CPR of a loved one. The review of the literature revealed that the majority of adult patients want family members to be present during the rescue procedures and to comfort them. ${ }^{8-10}$ Similar opinions were found by Grice et al in a group of 55 patients admitted to the hospital and their families, where $29 \%$ of patients and $47 \%$ of their families expressed a desire to be present during CPR. The most predominant reasons expressed for not wanting family present were the possibility of suffering for family and potential for longterm trauma after resuscitation. ${ }^{11}$ Farah et al claim that not all families will be willing to attend CPR. ${ }^{12}$ It is suggested that any family waiting in the waiting room, for whatever reason, should be provided with current information about the condition of their loved one. According to these authors, it is also advised to implement the criteria that allow the exclusion of certain family members from attendance during resuscitation. This applies especially to those who may be aggressive, hysterical or emotionally unstable to the extent of interfering with patient care, or who are under the influence of alcohol or drugs. ${ }^{12}$ Certainly, FPDR will not be experienced in a positive way by all families. One example of such negative effects was described by Van der Woning, who focused in the study on a family witnessing resuscitation of a loved one. Three out of five members of the family experienced distress within 6-12 months following the incident. ${ }^{13}$ Undoubtedly, one of the main ideas of FPDR is the desire to satisfy the emotional needs of patients and their relatives. It should be remembered, however, that the empathy experienced by the medical staff towards the patient and their family cannot be the only and decisive factor influencing the decision on the consent for relatives to participate during resuscitation. ${ }^{14}$

The studies by Chew regarding the opinions of Malaysian residents (N-184) are quite different, and the respondents strongly support FPDR. They show that $76.1 \%$ of the participants support the presence of family members during CPR. ${ }^{15}$ Similarly, in the studies by Barratt et al despite the lack of knowledge about CPR, $62.0 \%$ (N-35) of the respondents wanted to be present during resuscitation. ${ }^{16}$ The study by Ong et al shows that $73.1 \%$ of the surveyed population expressed support for the FPDR. ${ }^{17}$ Furthermore, Meyers et al presented results on the assessment of the attitudes of patients' families (N-25), who participated in the CPR and experienced the death of the nearest person. In addition, $80 \%$ of relatives said they would like to be present during CPR, and $96 \%$ of family members felt that they wanted to have a choice in this matter. In turn, $68 \%$ thought that FPDR helped the patient, and $64 \%$ claimed that the fact that they were present during resuscitation helped them to reconcile with the death of the nearest person. ${ }^{18}$

Doyle et al in their research showed that 94\% (N-51) of people who were present at CPR showed willingness to participate again, 74\% said that it would be easier to accept the death of a loved one, and 64\% consider FPDR beneficial to their dying relative. ${ }^{1}$ Other studies have shown similar positive consent for FDPR among their respondents, with $70 \%$ acceptance by family members ${ }^{10}$ and $72 \%$ by patients (N-200). ${ }^{9}$ Leske et al conducted a study on a group of 28 family members which indicate that the presence of relatives during CPR helps family members build trust in medical staff and at the same time maintain closeness to the loved ones. Families confirmed the fact that their presence was to support the family member emotionally, which they felt was beneficial to the patient at that time. ${ }^{19}$ A review of the literature, made by Oczkowski et al shows that inviting families to be present during resuscitation may reduce their symptoms of anxiety and depression, hence the benefits of FPDR have a decisive advantage over negative effects. ${ }^{20}$ Similar results brought the analysis of Mc Alvin et al and Porter et al. Similar results are found in studies involving family members of both adults and children and report the benefits of 
FPDR to outweigh any negative effects. ${ }^{21,22}$ Albarran et al conducted studies among patients who survived CPR (N-21) and patients admitted in an emergency (N-40), which indicated that both groups of respondents supported FPDR $72 \%$ and $58 \%$, respectively. ${ }^{23}$

In our research, the persons indicated by the respondents to be present during the resuscitation were most often spouses and their daughters. Similarly, in studies conducted by Benjamin et al the respondents accepted the fact of the presence of a family member during resuscitation, but a significant number of respondents would indicate only some family members and would like to have the right to designate such a person. ${ }^{9}$ However, acceptance for the presence of a family member during one's own resuscitation in our research was even lower: $21.2 \%$ of patients and $20.2 \%$ of family members. The sources of such attitudes could be explained by the lack of understanding of patient's rights, the lack of specialized medical knowledge, and the possibility of socially preserved canons of behaviour. The patient rights catalogue, which is directly related to the issues raised in this paper, is the patient's right to respect for private and family life. According to art. 47 of the Constitution of the Republic of Poland, everyone shall have the right to legal protection of his private and family life, of his honour and good reputation and to make decisions about his personal life. Among numerous manifestations of the implementation of this law, the right of the patient to decide on the potential presence of members of his family during medical procedures including CPR should be emphasized in a special way. The limitation of this right should, therefore, be exceptional and justified by specific conditions. An element of the patient's right to respect for dignity is also the right to die in peace and dignity. Its implementation requires care for the quality of life at its final stage, not only through the use of appropriate medical procedures but also by providing the patient with the necessary support from the relatives. ${ }^{24,25}$ Lack of knowledge about patient's rights in our research was indicated by half of the respondents. In the study by Meyers et al, $98 \%$ of the patient's families believed that the presence at resuscitation is their right ${ }^{26}$ similarly in studies by Beesley et $\mathrm{al}^{27}$ and Chew et al. ${ }^{15}$ The Emergency Nurses Association (ENA) supports the idea that the presence of the family during resuscitative and invasive procedures is the patient's right and also brings a number of benefits, both for the patients themselves and for their family members. ${ }^{28,29}$ The patient's family wants to be present with relatives, but at the same time they understand the need to maintain the confidentiality principle to ensure adequate quality of resuscitation and respect for patient dignity. According to our research, half of the surveyed patients $(48.8 \%)$ and their family members $(53.0 \%)$ participated in the BLS AED training, during which the effects of the training in the respondents' attitudes and experience were already assessed. Importantly, there are few studies assessing the effects of resuscitation-related training and treatment outcomes in patients. In an ideal situation, everyone should be familiar with CPR. There is no scientific evidence speaking for or against training of individuals from high-risk populations. However, training may reduce fear experienced by patients and family members, improve their emotional adaptation and make it easier for those in need to start CPR. ${ }^{32}$ Everyone reacts emotionally when they receive unfavourable, often critical information about the health of their relatives, sometimes realizing that this information can mean a meaningful loss, e.g. death of a loved one. From a psychological and social point of view, families have an innate need to be together with their loved ones, supporting each other in critical situations. Usually no one is prepared for the worst information about the health of the loved person. While medical staff focus on saving human life, they often forget about their relatives, who are now concentrating on understanding the situation and finding a way to overcome the crisis and stress that overwhelms them. Therefore, one of the goals of FPDR is to meet the emotional needs of both the patient and the family. Summing up, education can be an effective tool in changing the attitudes of both the patient and his relatives. Taking into account the results of the research, it should be stated that there is a need to prepare professional debates on FPDR, the aim of which would be to change the approach of medical staff to the FPDR, familiarize the patient and his family with their rights during hospitalization. Family members of patients undergoing CPR and invasive procedures should be able to be present at the patient's bed in accordance with the wishes of the patient. Family members are people defined by the patient or by his deputies in the case of a minor or a person without the ability to make decisions. Family members may be relatives or other relevant persons who provide support and with whom the patient has important relationships. All units dealing with patient care should have an approved written document (i.e. rules, procedure or standard of care) to present the option of family presence during resuscitation and invasive bedside procedures, including the roles 
and duties of the carer of the presence of the family. Policy creation has been repeatedly recommended in the literature. $5,6,30,31$

\section{Conclusion}

In our study, both patients and their family members had a negative attitude towards FPDR, which was contrary to what is known in the literature. Respondents (both patients and their relatives) had a low level of awareness that their potential to be present during CPR was included in the patient's rights.

\section{Implications for Clinical Practice}

Procedures that support the presence of the family during resuscitation and invasive procedures should be developed in hospitals that lack such policy. An interdisciplinary team should be created dedicated to the FDPR to develop own family presence program during CPR. Educational programs should be developed and should encompass the discussion of the benefits resulting from of FPDR for both the patient and the family members and the potential negative effects. Such procedures and education interventions should also outline family presence as an option for all parties involved, criteria for assessing family coping mechanisms to ensure uninterrupted patient care, including contraindications to the presence of family (e.g. family members who exhibit violent behaviour, uncontrollable emotional outbursts or people suspected of mistreatment), and means to support families who are not present. A designated family carer should be appointed to consult with the health care team during the resuscitation, whether families are present or not, and should support families before, during and after the event. It is imperative that standards be developed for all staff involved in FPDR to ensure the safety of patients, their families and staff. Formal hospital documents regarding the presence of the family during resuscitative procedures and CPR and the procedures involved in supporting patients, family members, and staff during such events should be prepared.

\section{Limitations of This Study}

There are several limitations to the present study. The study group included layperson respondents and medical professionals only from south-east Poland (Podkarpackie). The survey questionnaires are not standardised research instruments and the study sample represents the population of medical professionals from one region. Therefore, the generalisation of the results of the study findings is limited.
Additionally, interpretation of the differences in acceptance for FP between the current study and earlier reports may be associated with cultural differences in both Poland and Europe compared to the US, where most of the FP studies have been conducted.

\section{Disclosure}

The authors report no conflicts of interest in this work.

\section{References}

1. Doyle CJ, Post H, Burney RE, et al. Family participation during resuscitation: an option. Ann Emerg Med. 1987;16(6):673-675. doi:10.1016/S0196-0644(87)80069-0

2. Balogh-Mithell C. Is it time for family presence during resuscitation in the OR? AORN J. 2012;96(1):14-25. doi:10.1016/j.aorn.2011.06.013

3. Baumhover N, Hughes L. Spirituality and support for family presence during invasive procedures and resuscitations in adults. $\mathrm{Am}$ J Crit Care. 2009;18(4):357-366. doi:10.4037/ajcc2009759

4. Bossaert LL, Perkins GD, Askitopoulou H, et al. European resuscitation council guidelines for resuscitation 2015: section 11. The ethics of resuscitation and end-of-life decisions. Resuscitation. 2015;95:302-311. doi:10.1016/j.resuscitation.2015.07.033

5. Powers KA, Candela L. Nursing practices and policies related to family presence during resuscitation. Dimens Crit Care Nurs. 2017;36:53-59. doi:10.1097/DCC.0000000000000218

6. Powers K, Reeve CL. Factors associated with nurses' perceptions, self-confidence, and invitations of family presence during resuscitation in the intensive care unit: a cross sectional survey. Int $J$ Nurs Stud. 2018;87:103-112. doi:10.1016/j.ijnurstu.2018.06.012

7. Moreland P. Family presence during invasive procedures and resuscitation in the emergency department: a review of the literature. J Emerg Nurs. 2005;31(1):58-72. doi:10.1016/j.jen.2004.07.002

8. Mcmahon-Parkes K, Moule P, Benger J, et al. The views and preferences of resuscitated and non-resuscitated patients towards family-witnessed resuscitation: a qualitative study. Int J Nurs Stud. 2009;46(2):220-229. doi:10.1016/j.ijnurstu.2008.08.007

9. Benjamin M, Holger J, Carr M. Personal preferences regarding family member presence during resuscitation. Acad Emerg Med. 2004;11(7):750-753. doi:10.1111/acem.2004.11.issue-7

10. Eichhorn DJ, Meyers TA, Guzzetta CE, et al. Family presence during invasive procedures and resuscitation: hearing the voice of the patient. Am J Nurs. 2001;101(5):48-55. doi:10.1097/00000446200105000-00020

11. Grice AS, Picton P, Deakin CD. Study examining attitudes of staff, patients and relatives to witnessed resuscitation in adult intensive care units. Br J Anaesth. 2003;91(6):820-824. doi:10.1093/bja/aeg276

12. Farah MM, Thomas CA, Shaw KN. Evidence-based guidelines for family presence in the resuscitation room: a step-by-step approach. Pediatr Emerg Care. 2007;23(8):587-591. doi:10.1097/PEC.0b013e $318131 \mathrm{e} 482$

13. Van der Woning $M$. Relatives in the resuscitation area: a phenomenological study. Nurs Crit Care. 1999;4(4):186-192.

14. Leung NY, Chow SK. Attitudes of healthcare staff and patients' family members towards family presence during resuscitation in adult critical care units. J Clin Nurs. 2012;21(13-14):2083-2093. doi:10.1111/ j.1365-2702.2011.04013.x

15. Chew KS, Ghani ZA. Attitudes and perceptions of the general malaysian public regarding family presence during resuscitation. Singapore Med J. 2014;55(8):439-442. doi:10.11622/smedj.2014104

16. Barratt $\mathrm{F}$, Wallis DN. Relatives in the resuscitation room: their point of view. J Accid Emerg Med. 1998;15(2):109-111. doi:10.1136/ emj.15.2.109 
17. Ong ME, Chung WL, Mei JS. Comparing attitudes of the public and medical staff towards witnessed resuscitation in an Asian population. Resuscitation. 2007;73(1):103-108. doi:10.1016/j.resuscitation.2006.08. 007

18. Meyers TA, Eichhorn D, Guzzetta CE. Do families want to be present during CPR? A retrospective survey. J Emerg Nurs. 1998;24 (5):400-405. doi:10.1016/S0099-1767(98)70005-4

19. Leske JS, McAndrew NS, Brasel KJ. Experiences of families when present during resuscitation in the emergency department after trauma. J Trauma Nurs. 2013;20(2):77-85. doi:10.1097/JTN.0b013e31829600a8

20. Oczkowski S, Mazzetti I, Cupido C, Fox-Robichaud AE. The offering of family presence during resuscitation: a systematic review and meta-analysis. J Intensive Care. 2015;3(41):1-11. doi:10.1186/ s40560-015-0107-2

21. McAlvin SS, Carew-Lyons A. Family presence during resuscitation and invasive procedures in pediatric critical care: a systematic review. Am J Crit Care. 2014;23(6):477-484. doi:10.4037/ajcc2014922

22. Porter J, Cooper SJ, Sellick K. Attitudes, implementation and practice of Family Presence During Resuscitation (FPDR): a quantitative literature review. Int Emerg Nurs. 2013;21(1):26-34. doi:10.1016/j. ienj.2012.04.002

23. Albarran J, Moule P, Benger J, McMahon-Parkes K, Lockyer L. Family witnessed resuscitation: the views and preferences of recently resuscitated hospital inpatients, compared to matched controls without the experience of resuscitation survival. Resuscitation. 2009;80 (9):1070-1073. doi:10.1016/j.resuscitation.2009.05.020

24. Jacek A, Ożóg K. Observance of patient's rights by medical personnel. Hygeia Public Health. 2012;47(3):264-271.

25. Constitution of the Republic of Poland of April 2, 1997 (Journal of Laws 1997, item 483 with amendments).
26. Meyers TA, Eichhorn DJ, Guzzetta CE, et al. Family presence during invasive procedures and resuscitation. Am J Nurs. 2000;100 (2):32-42.

27. Beesley SJ, Hopkins RO, Francis L, et al. Let them in: family presence during intensive care unit procedures. Ann Am Thorac Soc. 2016;13(7):1155-1159. doi:10.1513/AnnalsATS.201511-754OI

28. Helmer SD, Smith RS, Dort JM, Shapiro WM, Katan BS. Family presence during trauma resuscitation: a survey of AAST and ENA members. American Association for the Surgery of Trauma. Emergency Nurses Association. J Trauma. 2000;48(6):1015-1022. doi:10.1097/00005373-200006000-00004

29. Emergency Nurses Association (ENA). Position statement - Family presence during invasive procedures and resuscitation in the emergency department; 2014. Available from: https://www.ena.org/docs/ default-source/resource-library/practice-resources/cpg/familypresen cesynopsis3bdad0aaaeeb4370856e849f26e553a3.pdf?sfvrsn= 21ca66b_16 Accessed February 12, 2018.

30. MacLean SL, Guzzetta CE, White C, et al. Family presence during cardiopulmonary resuscitation and invasive procedures: practices of critical care and emergency nurses. J Emerg Nurs. 2003;29 (3):208-221. doi:10.1067/men.2003.100

31. Gutysz-Wojnicka A, Ozga D, Dyk D, et al. Family presence during resuscitation - The experiences and views of polish nurses. Intensive Crit Care Nurs. 2018;46:44-50. doi:10.1016/j.iccn.2018. 02.002

32. Bhanji F, Finn JC, Lockey A, et al. Part 8: education, implementation, and teams: 2015 International consensus on cardiopulmonary resuscitation and emergency cardiovascular care science with treatment recommendations. Circulation. 2015;132(supp11):S242-S268. doi:10. 1161/CIR.0000000000000277
Patient Preference and Adherence

\section{Publish your work in this journal}

Patient Preference and Adherence is an international, peer-reviewed, open access journal that focusing on the growing importance of patient preference and adherence throughout the therapeutic continuum. Patient satisfaction, acceptability, quality of life, compliance, persistence and their role in developing new therapeutic modalities and compounds to optimize clinical outcomes for existing disease states are major areas of interest for the journal. This journal has been accepted for indexing on PubMed Central. The manuscript management system is completely online and includes a very quick and fair peer-review system, which is all easy to use. Visit http:// www.dovepress.com/testimonials.php to read real quotes from published authors. 